
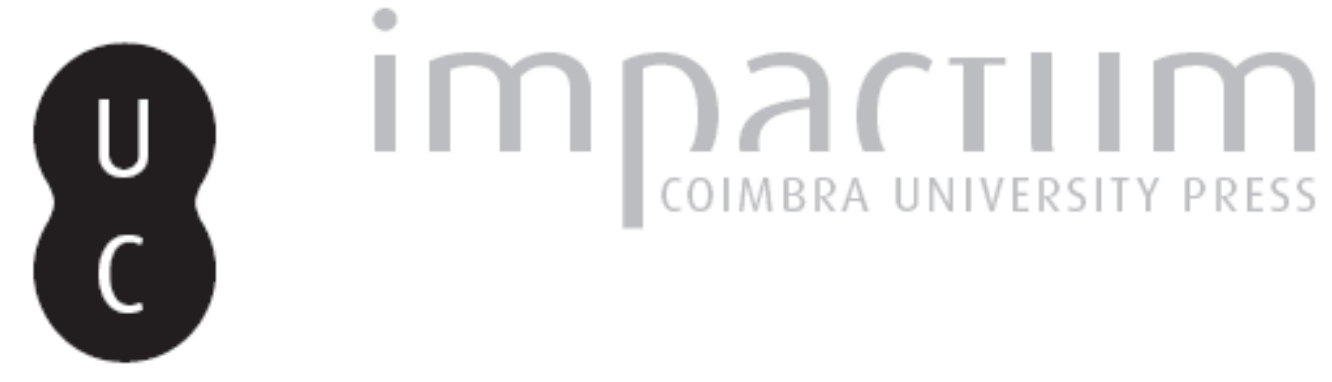

\title{
Carta Social Municipal: uma estratégia de intervenção integrada
}

Autor(es): $\quad$ Cordeiro, A. M. Rochette; Santos, Lúcia

Publicado por: $\begin{aligned} & \text { Faculdade de Letras da Universidade de Coimbra, Departamento de } \\ & \text { Geografia }\end{aligned}$

URL

persistente:

URI:http://hdl.handle.net/10316.2/30270

DOI:

DOI:http://dx.doi.org/10.14195/0871-1623_32_29

Accessed : $\quad$ 26-Apr-2023 02:03:03

A navegação consulta e descarregamento dos títulos inseridos nas Bibliotecas Digitais UC Digitalis, UC Pombalina e UC Impactum, pressupõem a aceitação plena e sem reservas dos Termos e Condições de Uso destas Bibliotecas Digitais, disponíveis em https://digitalis.uc.pt/pt-pt/termos.

Conforme exposto nos referidos Termos e Condições de Uso, o descarregamento de títulos de acesso restrito requer uma licença válida de autorização devendo o utilizador aceder ao(s) documento(s) a partir de um endereço de IP da instituição detentora da supramencionada licença.

Ao utilizador é apenas permitido o descarregamento para uso pessoal, pelo que o emprego do(s) título(s) descarregado(s) para outro fim, designadamente comercial, carece de autorização do respetivo autor ou editor da obra.

Na medida em que todas as obras da UC Digitalis se encontram protegidas pelo Código do Direito de Autor e Direitos Conexos e demais legislação aplicável, toda a cópia, parcial ou total, deste documento, nos casos em que é legalmente admitida, deverá conter ou fazer-se acompanhar por este aviso.

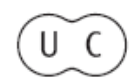




\title{
Carta Social Municipal: uma estratégia de intervenção integrada
}

\author{
A. M. Rochette Cordeiro \\ Departamento de Geografia e Centro de Estudos de Geografia e Ordenamento do Território (CEGOT). Faculdade de Letras da Universidade de Coimbra. \\ rochettecordeiro@fl.uc.pt
}

\section{Lúcia Santos}

Bolseira de Investigação da Faculdade de Letras da Universidade de Coimbra.

luciarsantos@gmail.com

\section{Resumo:}

As transformações observadas na década de 70 relativamente a valores pessoais, sociais e culturais, bem como a aspetos laborais tiveram significativas repercussões na evolução da área social. Se até esse momento esta era restrita e deveras simplificada, após este período sofreu uma grande modificação, alargando-se e tornando-se mais complexa.

No momento atual parece ser inquestionável que a ação social apresenta um papel imprescindível numa sociedade cuja evolução deu origem a novas necessidades e modos de vida, vendo-se, assim, confrontada com uma crescente procura de diferentes respostas sociais de apoio aos indivíduos carenciados e respetivas famílias.

A necessidade de se equacionar uma Carta Social Dinâmica surge como resposta à inexistência de uma política sustentável de ação social em termos municipais que apontasse medidas concretas para os desafios crescentes.

Palavras-chave: Carta Social. Metodologia e Instrumentos de Planeamento.

\section{Résumé:}

Charte Sociale Municipale: une stratégie d'intervention intégrée

Les transformations observées dans les années 70 relatives aux valeurs personnelles, sociales et culturelles, ainsi qu'aux aspects laborieux ont eu de grandes répercussions sur l'évolution du secteur social. Si celle- ci était à ce moment là restreinte et réellement simplifiée, elle va après cette période connaitre un grand changement en s'élargissant et en devenant plus complexe.

Actuellement, il est incontestable que l'action sociale à un rôle majeur dans une société dont l'évolution a donné lieu à de nouveaux besoins et modes de vie et pour cela, elle est confrontée à une demande croissante relative aux aides sociales des individus défavorisés ainsi qu'á leurs familles.

La nécessité de se doter d'une Charte Sociale Dynamique surgit comme une réponse à l'inexistence d'une politique durable d'action sociale au niveau municipal qui indique des mesures concrètes aux défis croissants.

Mots-clés: Charte Sociale, Méthodologie et Instruments de Planification.

\section{Abstract:}

Municipal Social Report: na integrated intervention strategy

During the 70s, there were major changes in personal, cultural and social mindsets. One of the strongest impacts on the social area, was Labor. Until then, it was restricted and quite simple, but after this period has undergone a major change, widening and becoming more complex.

Today, it seems to be no doubt that social wellfare has an essential role in a society, whose evolution has given rise to new needs and new ways of life, being confronted with a growing demand for different social responses to support both individuals and the family needs.

The need for a Dynamic Social Report appears to be a response to the absence of a municipal policy of sustainable social action, and aims to define concrete measures for the growing challenges.

Keywords: Social Report. Methodology and Planning Instruments. 


\section{Desenvolvimento do sistema social}

De acordo com o plasmado na Constituição da República Portuguesa sobre direitos e deveres sociais, todos os cidadãos têm direito a uma efetiva segurança social, cabendo ao Estado organizar, coordenar e subsidiar um sistema de segurança social unificado e descentralizado.

O sistema de segurança social estatal deverá, assim, proteger os cidadãos na doença, velhice, invalidez, viuvez e orfandade, bem como no desemprego e em todas as outras situações de falta ou diminuição de meios de subsistência ou de capacidade para o trabalho.

Mas a proteção dos cidadãos não cabe apenas ao Estado, sendo a prestação de serviços à população efetuada também por entidades coletivas não estatais, prática que atravessa os séculos. Desde a fundação da nacionalidade portuguesa, com clara inspiração nos valores cristãos, que se assiste ao desenvolvimento de esforços tendentes a dar corpo ao sentimento do dever moral de proteção contra situações de necessidade nos planos individual e familiar.

Até ao fim da Idade Média, a par da beneficência individual e familiar, foi-se desenhando uma organização embrionária da assistência privada sem fins lucrativos, que conduziu à primeira grande reforma da assistência, com a criação das Santas Casas da Misericórdia, que se multiplicaram um pouco por todo o país, tornando-se, a nível local, no grande pólo da assistência privada sem fins lucrativos, tanto na saúde, como na ação social.

Até ao século XIX, com incidência e modalidades variáveis, o fulcro das respostas sociais continuou a assentar na beneficência individual e familiar e nas organizações religiosas, predominantemente dirigidas para situações de doença. A prestação de serviços à população assumiu neste longo período um carácter essencialmente caritativo e assistencialista.

Entretanto, o desenvolvimento das condições de democraticidade política, o reforço dos movimentos sociais e uma conceção crescente dos direitos sociais fazem emergir outros atores como entidades responsáveis por respostas sociais. No século XIX, especialmente nos principais centros industriais-urbanos, assiste-se, assim, ao aparecimento de um importante movimento mutualista que, em especial ao longo da segunda metade desse século, estimulou um rápido crescimento do número de associações de socorros mútuos e dos respetivos associados. Estas apresentavam como seus principais objetivos, a prestação de cuidados médicos e o fornecimento de medicamentos, a atribuição de prestações pecuniárias nas situações de incapacidade temporária ou permanente para o trabalho e a atribui- ção de subsídios de funeral. Foi assim que associações mutualistas, associações cívicas e empresas fundam e gerem serviços e equipamentos sociais a favor dos seus sócios, da comunidade ou dos seus empregados.

Nem a intervenção, já no século XX, da Previdência Social através do Instituto de Obras Sociais, alterou até aos anos 70 o panorama da rede, tendo-se entretanto começado a verificar o incremento dos serviços e equipamentos sociais de natureza privada, mas com fins lucrativos.

A partir da segunda metade da década de 70 , como resultado conjugado da tomada de consciência dos direitos sociais e da dinâmica social então criada com o advento da democracia, verificou-se o aparecimento de um número assinalável de iniciativas, nem sempre concretizado em volume de investimento.

O Estado, entretanto, rapidamente reconheceu o papel primordial das entidades privadas sem fins lucrativos na gestão dos serviços e equipamentos sociais, passando a apoiar, mas também a fiscalizar, a sua atividade e o seu funcionamento. O desenvolvimento da rede potenciou-se, assim, quer pela capacidade de mobilização de meios, nomeadamente públicos, quer pela motivação das instituições, mas permaneceu em aberto a delimitação do espaço que irá ser ocupado pela atividade privada com fins lucrativos, onde se verificam novas iniciativas numa base sustentada.

Todavia, num mundo como o atual, em que todos os dias se colocam novos problemas, criando novas necessidades, torna-se obrigatório o permanente repensar das soluções já existentes, com vista a um incremento da eficiência na utilização dos meios disponíveis, e a constante criação de novas respostas, de modo a responder às crescentes carências da população.

Estes novos problemas advêm da crescente falta de capacidade das famílias em responderem adequadamente em áreas como a proteção, a socialização e a prestação de cuidados na infância, velhice e doença, mas também da existência de um grupo cada vez mais vasto de cidadãos que, por diversas razões, perderam involuntariamente os laços familiares e, com eles, os laços com a própria sociedade envolvente.

Uma intervenção cada vez maior da mulher no mercado de trabalho, quer por motivos económicos, que se prendem com o equilíbrio do orçamento familiar, quer pelo desejo de realização pessoal e profissional, que se prende com os novos valores cívicos e individuais, transformou por completo a estrutura e organização familiar, obrigando em determinado momento ao aparecimento crescente de respostas sociais destinadas à população-alvo "Infância e Juventude". 
Neste mesmo contexto, também o acentuar da partilha de responsabilidades educativas entre a família e a sociedade na infância e na idade pré-escolar, bem como a carência de, depois dessa idade, prolongar o apoio às famílias e à ação educativa dos estabelecimentos de ensino, conduziram à necessidade de serviços e equipamentos sociais dirigidos ao grupo-alvo "Crianças e Jovens".

O enfoque pedagógico e integrador das respostas sociais dirigidas a estas necessidades tornou-se, entretanto, também predominante nos serviços e equipamentos sociais dirigidos aos grupos-alvo "Crianças e Jovens com Deficiência" e "Crianças e Jovens em Situação de Perigo".

Paralelamente, as famílias manifestam necessidades de apoio à população-alvo "População Adulta", a qual inclui os grupos-alvo "Pessoas Idosas", "Pessoas Adultas com Deficiência", "Pessoas em Situação de Dependência", "Pessoas com Doença do Foro Mental ou Psiquiátrico" e "Pessoas Sem-Abrigo". Pela amplitude de respostas sociais exigidas e pelo ritmo a que se observa nos tempos atuais a problemática do envelhecimento da população portuguesa destaca-se o grupoalvo "Pessoas Idosas".

Este crescente e generalizado envelhecimento da população, em particular a partir da década de 70 , provocado pela melhoria das condições de vida, o que se deve, entre outros aspetos, ao desenvolvimento económico, aos progressos da medicina e à melhor cobertura da rede de saúde pública, foi determinante para o aparecimento da crescente necessidade de respostas sociais dirigidas a este grupo-alvo. Uma vez mais a integração da mulher no mercado de trabalho, mas também a própria transformação da estrutura e organização familiar, com a nuclearização dos agregados familiares e o aparecimento dos isolados, foram determinantes para esta realidade.

Com a criação de uma rede de serviços e equipamentos sociais para o grupo-alvo "Pessoas Idosas" pretende-se disponibilizar o espaço, o tempo e as oportunidades de que estas necessitam para se manterem ativas e participantes na vida social, facilitar a fruição de benefícios a que muitas não tiveram acesso durante a vida ativa e prestar cuidados de assistência física, psicológica e social que assegurem qualidade de vida, principalmente às que vão perdendo a sua autonomia e não têm suporte familiar.

Com o crescimento progressivo da população idosa, sobretudo dos grupos etários mais avançados, é também maior a probabilidade de ocorrência de situações de dependência física, psíquica e social, o que tem vindo a aumentar a necessidade de respostas sociais mais adequadas a estas situações, não só no âmbito do social, mas também da própria saúde.

Mas as necessidades de apoio às famílias não se ficam apenas pelo atendimento dos seus membros menores e idosos quando estas não o conseguem fazer, merecendo a população-alvo "Família e Comunidade" igual atenção. É o caso das famílias de menores recursos económicos, que integram o grupo-alvo "Família e Comunidade em Geral", e de um conjunto crescente de pessoas que, por vários motivos, romperam a ligação à família e à comunidade, que integram os gruposalvo "Pessoas com VIH/SIDA e suas Famílias", "Pessoas Toxicodependentes" e "Pessoas Vítimas de Violência Doméstica”.

A rede de serviços e equipamentos sociais dirigida a esta população-alvo, que cada vez é mais numerosa, deve ser adaptada em função do risco social a que se encontra sujeita, assumindo-se como a única alternativa viável para a obtenção de um mínimo de dignidade humana e para o acesso a um primeiro patamar de reinserção social para estes cidadãos.

A nova cultura de solidariedade pela qual se tem vindo a orientar a intervenção junto destes grupos de risco que só recentemente apareceram ou passaram a ser objeto de intervenção social, está na origem do impulso dado nas respostas sociais prestadas a uma das categorias mais antigas em situação de desfavorecimento: os cidadãos com deficiência.

O objetivo da intervenção social junto dos cidadãos com deficiência apresenta, porém, duas faces: por um lado procura-se fazer com que as respostas sociais existentes se adaptem às suas necessidades específicas, sua vertente principal, e, por outro lado, quando isso é impossível ou não é tecnicamente recomendável, têm-se vindo a desenvolver serviços especializados que visam promover a reabilitação, fornecer a ajuda que permita uma vida normal ou compensar a deficiência e garantir a dignidade humana.

Através desta rede de serviços e equipamentos sociais criada e em constante desenvolvimento pretende-se fornecer resposta a todos aqueles que dela necessitam, objetivo difícil de alcançar, dada a natureza evolutiva dos problemas e necessidades, dos direitos e das expectativas.

Parece ser incontornável a discussão que por vezes se desenvolve em torno da necessidade de todas estas respostas serem adequadamente dimensionadas e distribuídas e responderem com elevados níveis de eficiência às carências e problemáticas sociais existentes. Nesse sentido, tem-se vindo a constatar a efetiva ne- 
cessidade de um instrumento de planeamento da rede de serviços e equipamentos sociais capaz de potenciar de um modo integrado e dinâmico todas as ofertas.

\section{Aparecimento e evolução da Carta da Segurança Social. Um projeto desenvolvido pela Tutela}

As transformações verificadas a nível mundial no decorrer da década de 70 , nomeadamente no que se refere a valores pessoais, sociais e culturais e a aspetos laborais, tiveram repercussões significativas na evolução que a área social observou. Se até este momento a área social era restrita e deveras simplificada, após este período a área social sofreu uma grande modificação, alargando-se e tornando-se cada vez mais complexa, de acordo com as necessidades manifestadas pela população.

É hoje um dado inquestionável que a ação social tem um papel preponderante e imprescindível a desempenhar numa sociedade cuja evolução deu origem não só a novas necessidades, mas também a novos modos de vida, vendo-se, assim, confrontada com uma crescente procura de novas respostas sociais de apoio aos indivíduos carenciados e suas respetivas famílias.

Portugal não foi alheio a todo este conjunto de transformações, apesar de apresentar, como é hábito, algumas dificuldades de cariz organizacional, nomeadamente no que respeita ao adequar da oferta à procura, à luta contra a exclusão social e o isolamento e à inserção social de pessoas carenciadas e de minorias étnicas.

Foi neste contexto de desenvolvimento socioeconómico que a necessidade de criação de uma "Carta Social" surgiu, como resposta à necessidade de criar uma verdadeira política sustentável de ação social, apontando medidas e iniciativas concretas para os desafios crescentes da área social, designadamente no que se refere ao relacionamento entre as entidades das redes solidária e privada.

$\mathrm{Na}$ realidade, o desenvolvimento de um instrumento com carácter oficial, global e de fácil acesso contendo a informação mais relevante relativa à rede de serviços e equipamentos sociais era um objetivo que atravessava há já quase quatro décadas os Ministérios do Trabalho e Solidariedade Social em Portugal, mas só na década de 70 o caminho para o alcançar começou a ser traçado.

A primeira ideia consistiu na elaboração de um "Atlas Social", tendo, a partir desse momento, a vontade de materializar este projeto conduzido, nas décadas seguintes, ao aparecimento da "Carta da Segurança So- cial", da "Rede de Serviços e Equipamentos da Segurança Social” (RSESS) e, mais tarde, por iniciativa do Centro Regional de Segurança Social (CRSS) de Lisboa e Vale do Tejo, de um inventário (Ré et al., 2000).

Todavia, a plena concretização deste objetivo apenas teve lugar com o início da implementação da "Carta Social", através do "Estudo de Localização e Caracterização dos Equipamentos e Serviços Sociais", desenvolvido entre 1998 e 1999. No ano de 2000 foi publicada a "Carta Social - Rede de Serviços e Equipamentos" pelo Ministério do Trabalho e da Solidariedade Social, atualizada anualmente (Ré et al., 2000).

Esta "Carta Social" do Ministério do Trabalho e da Solidariedade Social pretendia, segundo a Tutela, ser um instrumento multiusos de extrema flexibilidade nos domínios da investigação social, da preparação da tomada de decisão e da facilidade de acesso à informação por parte dos cidadãos (Ré et al., 2000).

No domínio da investigação social visa disponibilizar informação sobre as dinâmicas sociais nos diversos territórios e o grau de disponibilidade dos serviços sociais. Enquanto ferramenta vocacionada para a preparação da tomada de decisão pretende fornecer aos diferentes atores sociais (públicos e privados) informação integrada para a correta determinação do volume do esforço e da localização prioritária da intervenção social, nomeadamente traduzida em investimento público. Por último, para facilitar o acesso à informação por parte dos cidadãos, ambiciona potenciar a informação sobre a localização dos serviços e equipamentos sociais existentes (RÉ et al., 2000).

Esta "Carta Social" assume-se, no seu essencial, como um conjunto de bases de dados comportando diversos ficheiros temáticos relacionáveis entre si, com uma base geográfica desagregada aos diversos níveis estatísticos, integrando informação relevante para a caracterização da situação social e suscetível de ser permanentemente atualizável.

\section{Criação do "Programa Rede Social"}

Após o desenvolvimento e publicação da "Carta Social" pelo Ministério do Trabalho e da Solidariedade Social rapidamente se percebeu que esta não passava de um diagnóstico estático da informação relativa à rede de serviços e equipamentos sociais e que para se assumir verdadeiramente como instrumento de planeamento o documento deveria passar a integrar uma componente prospetiva direcionada para a programação da rede de serviços e equipamentos sociais. 
É neste contexto que surge em 1997, no seguimento da afirmação de uma nova geração de políticas sociais ativas, baseadas na responsabilização e mobilização do conjunto da sociedade e de cada indivíduo para o esforço de erradicação da pobreza e da exclusão social, o "Programa Rede Social", criado através da Resolução do Conselho de Ministros n. ${ }^{\circ}$ 197/97 de 18 de Novembro de 1997 e da Declaração de Retificação n. ${ }^{\circ} 10-0 / 98$, posteriormente retificada pelo Despacho Normativo $n^{\circ} 8 / 2002$ de 12 de Fevereiro e com as alterações introduzidas pelo Decreto-Lei n. ${ }^{\circ}$ 115/2006 de 14 de Junho.

A "Rede Social" apresenta-se, assim como um fórum de articulação e congregação de esforços baseado na adesão por parte das autarquias e de entidades públicas ou privadas com vista à erradicação ou atenuação da pobreza e da exclusão e à promoção do desenvolvimento social. Pretendia-se com ela fomentar a formação de uma consciência coletiva dos problemas sociais e contribuir para a ativação dos meios e agentes de resposta e para a otimização possível dos meios de ação nos locais, numa lógica do que se pode vir a considerar como uma "territorialização" da área social.

O que se propõe é que em cada comunidade se criem novas formas de conjugação de esforços, se avance na definição de prioridades e se planeie de forma integrada e integradora o esforço coletivo, através da constituição de um novo tipo de parceria entre entidades públicas e privadas com intervenção nos mesmos territórios. Esta parceria baseia-se na igualdade entre os parceiros, na consensualização dos objetivos e na concertação das ações desenvolvidas pelos diferentes agentes locais.

$O$ referido planeamento integrado e integrador do esforço coletivo que a "Rede Social" propõe assume como instrumentos essenciais a elaboração de Diagnósticos Sociais, de Planos de Desenvolvimento Social e de Planos de Ação.

Cada um destes instrumentos de planeamento apresenta objetivos e metodologias diferenciadas. Enquanto o Diagnóstico Social se apresenta como um instrumento dinâmico sujeito a atualizações periódicas, resultantes da participação dos diferentes parceiros e onde devem estar identificadas as necessidades e os problemas prioritários, bem como os recursos, potencialidades e constrangimentos de cada território municipal, o Plano de Desenvolvimento Social, com base nas prioridades definidas, determina os eixos de intervenção e os objetivos estratégicos para um horizonte temporal de três anos. Estes eixos de intervenção e objetivos estratégicos são operacionalizados através de um Plano de Ação anual, concertados e concretizados pelos diferentes parceiros.

\section{Carta Social Municipal: uma estratégia de intervenção integrada}

Com a criação do "Programa Rede Social" introduziu-se uma importante componente de programação no tão desejado planeamento da rede de serviços e equipamentos sociais, com a identificação de objetivos a atingir num horizonte temporal definido, complementando-se, assim, a "Carta Social", que apesar dos objetivos ambiciosos, na prática corresponde unicamente a uma base de dados atualizada da rede de serviços e equipamentos sociais existentes, que dá acesso a um conjunto de informação de base relativa à sua caracterização geral.

Mas analisando estes dois instrumentos, e embora a criação do "Programa Rede Social" tenha suprido algumas das limitações que a "Carta Social" apresentava, na realidade, continua a observar-se a ausência de componentes essenciais para um efetivo planeamento da rede de serviços e equipamentos sociais.

Como facilmente se constata, e mesmo observando as duas ferramentas em conjunto, permanece em falta uma componente de caracterização do território, de análise prospetiva e de diagnóstico evolutivo, que, complementadas com uma forte componente geográfica, são determinantes para o planeamento da rede de serviços e equipamentos sociais.

Variáveis como as condicionantes físicas, a rede de acessibilidades, as dinâmicas demográficas e socioeconómicas e as projeções demográficas, quer da população residente total, quer por população e grupo-alvo, entre muitas outras, são essenciais para a perceção da realidade presente e futura de um território e a base de qualquer processo de planeamento estruturado (Figura 1a, b, c e d).

A análise destas variáveis geográficas associada à realização de análises comparativas entre diferentes momentos e à utilização de cartografia temática e de informação alfanumérica georreferenciada abre ainda um segundo conjunto de possibilidades a que nenhum dos dois documentos anteriores permitia acesso, tornando-se possível dar resposta a um vasto conjunto de questões que todos os decisores devem ter em consideração aquando de um processo de planeamento (CORDEIRo et al., 2007-2008).

Entre muitas outras possibilidades, a forte componente geográfica permite a realização de análises da 

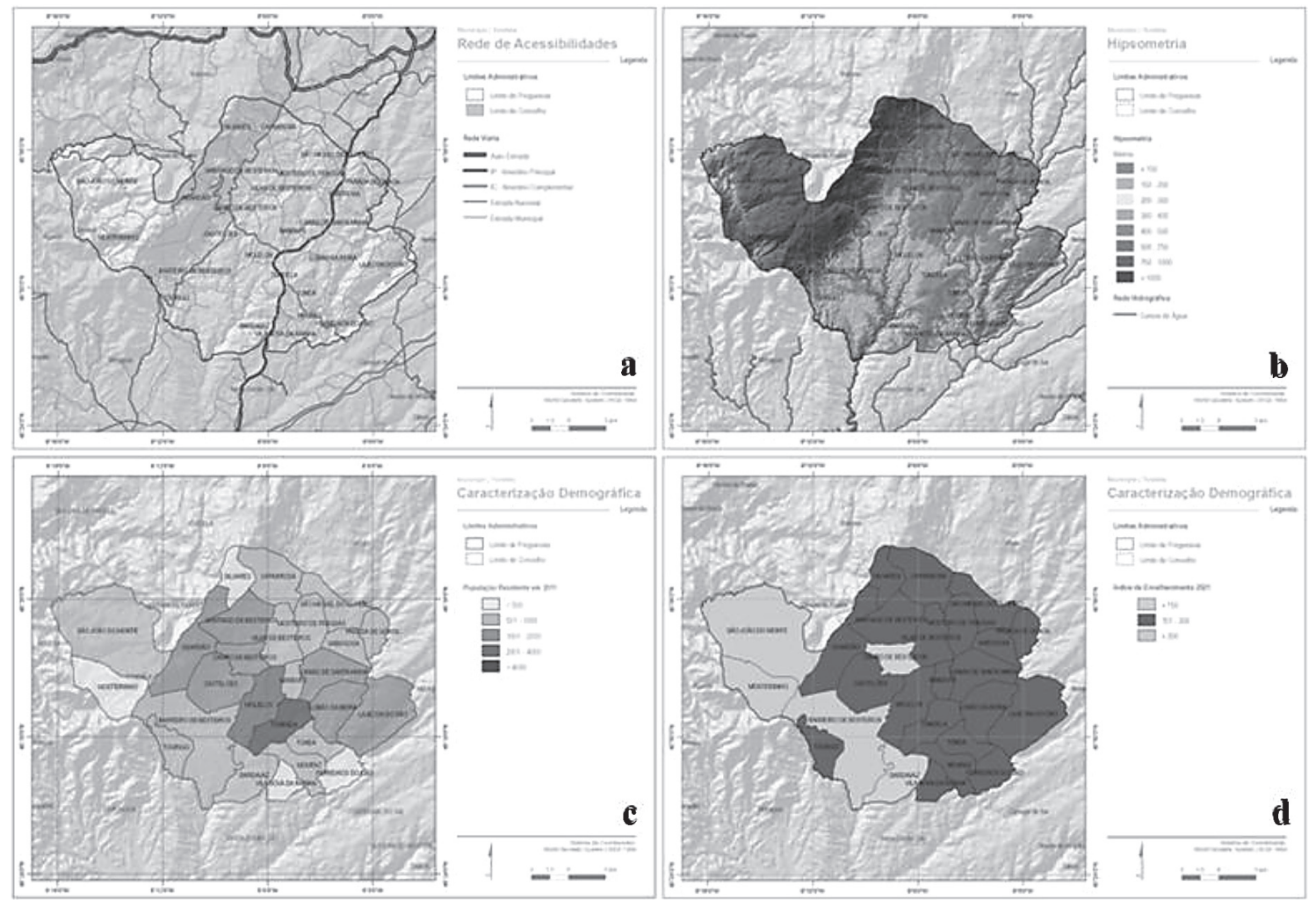

Figura 1

Algumas das variáveis geográficas a observar na elaboração de uma Carta Social Municipal: (a) condicionantes físicas, (b) rede de acessibilidades, (c) dinâmicas demográficas e (d) projeções demográficas (CoRDEIRO et al., 2011).

residência dos utentes (Figura 2 ), de modo a conhecer as movimentações da população, e a criação de cenários e a sua análise imediata (Figura 3), que permite introduzir novos níveis de informação, realizar previsões, desenhar futuros alternativos e estabelecer ou mesmo redefinir estratégias em tempo real (CORDEIRO et al., 2007-2008).

Do mesmo modo, verifica-se, igualmente, a possibilidade de integrar e analisar de modo integrado a informação respeitante a outras áreas de intervenção no domínio das políticas sociais que ultrapassem as respostas sociais típicas, único objeto de análise da "Carta Social".

Anteriormente descuradas, variáveis como as prestações pecuniárias (Rendimento Social de Inserção e Complemento Solidário para Idosos), as prestações em espécie (Programa Comunitário de Ajuda Alimentar a Carenciados), as outras políticas, programas e medidas, a comissão de proteção de crianças e jovens, a componente de apoio à família e a rede nacional de cuidados continuados passam agora a ser consideradas, possibilitando um mais fiel retrato da realidade social de um determinado território e, consequentemente, um planeamento mais próximo das reais necessidades da população (Figura 4).

Torna-se, assim, por demais evidente que só com a realização de um diagnóstico social globalizante e integrado, que caracterize não só os mecanismos de ação social de combate à pobreza e à exclusão social, mas que avalie também a sua relação com as diferentes dinâmicas do território, se torna possível a identificação da verdadeira dimensão das carências e problemáticas sociais existentes.

Foi com base nestas constatações que começou a ser desenvolvida investigação no âmbito da concretização de uma "Carta Social Municipal", através de uma estratégia de intervenção integrada, acrescendo-se ainda aos fatores já referidos a necessidade de criar um instrumento aglutinador de toda esta informação. Pretendeu-se com este projeto, não só colmatar as lacunas existentes, mas também agrupar numa plataforma única todas as ferramentas existentes atualmente.

A concretização da "Carta Social Municipal" obedeceu, naturalmente, a uma metodologia específica que integra um conjunto articulado de fases (Figura 5). 


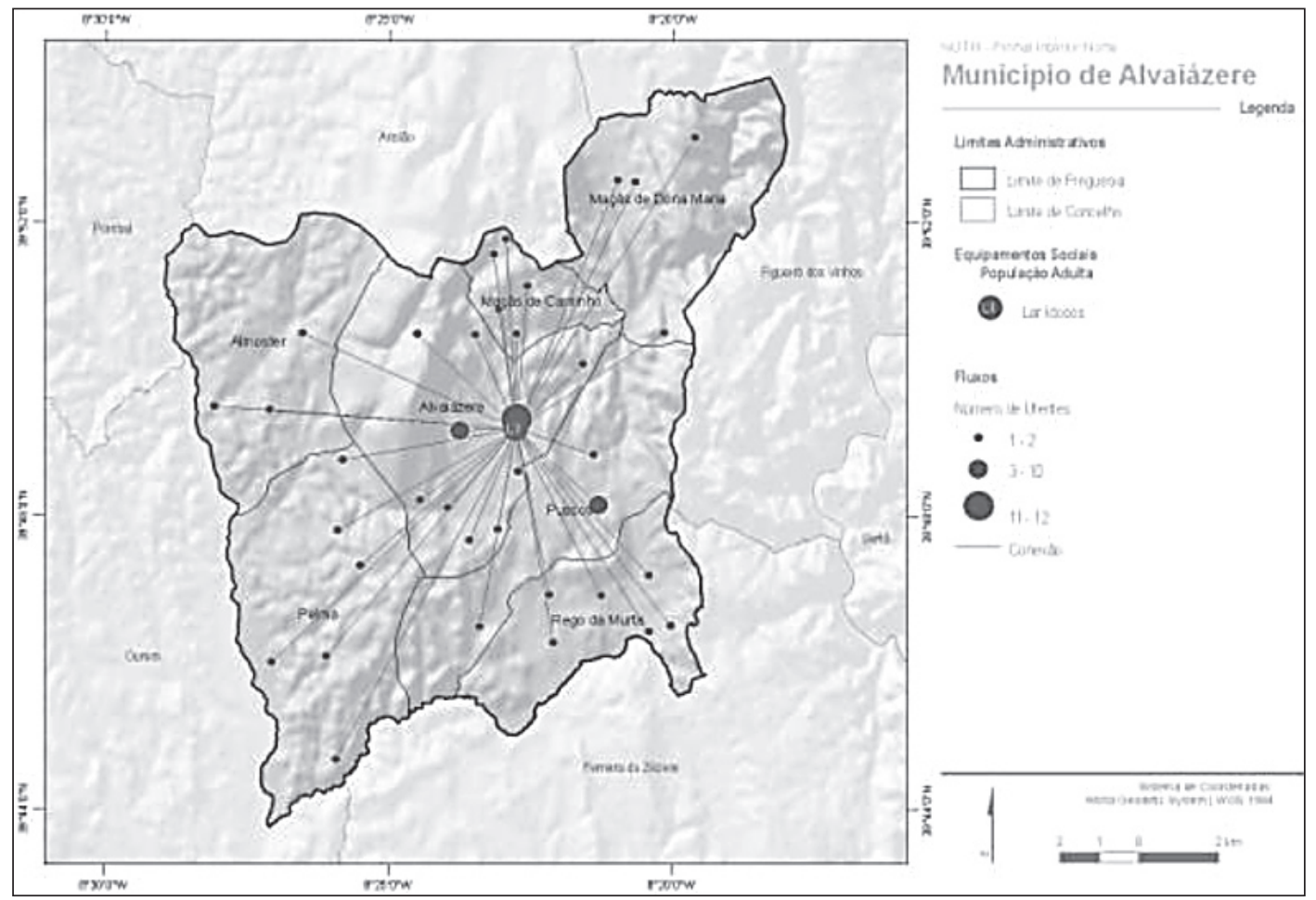

Figura 2

Análise da residência de origem dos utentes do lar de idosos (CoRDEIRo et al., 2012).

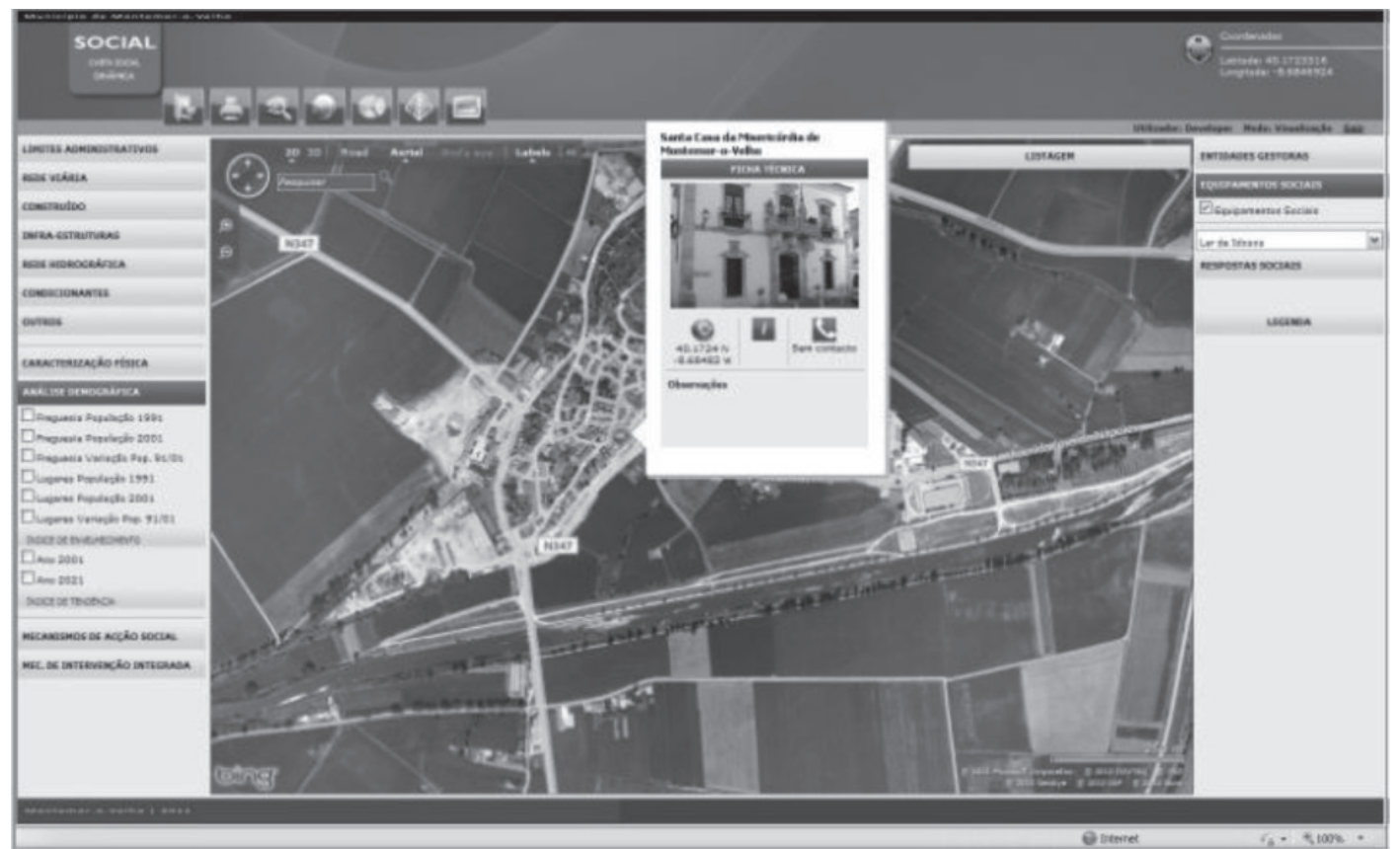

Figura 3

Criação de cenários (CoRDEIRo et al., 2011). 

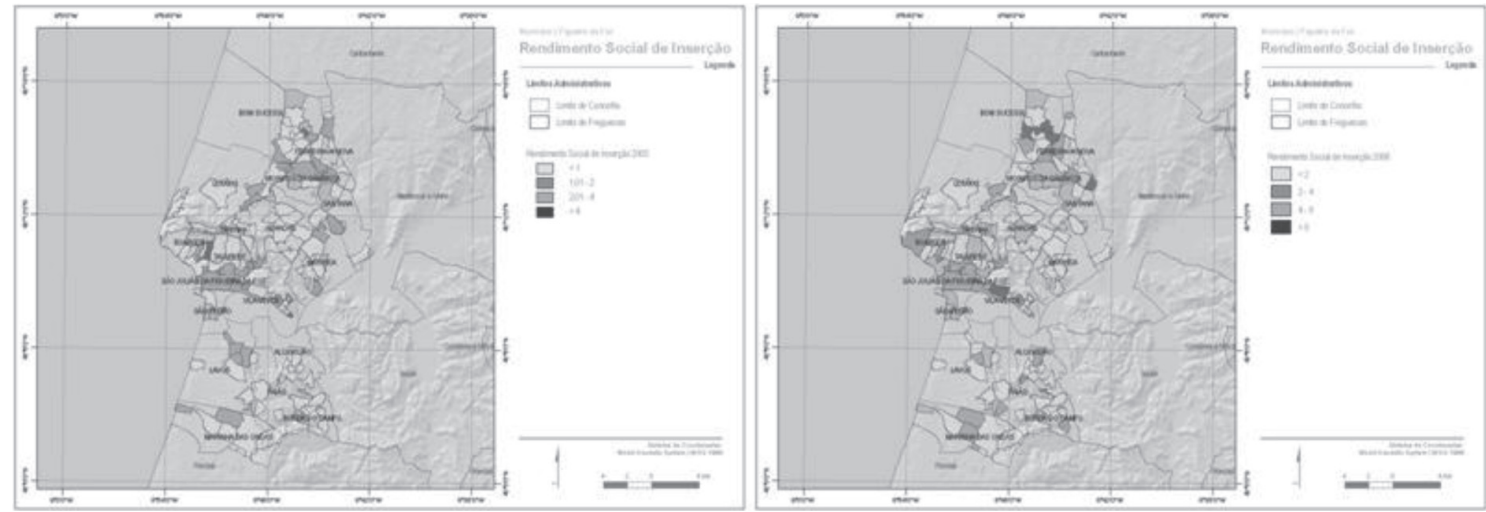

Figura 4

Evolução do Rendimento Social de Inserção entre 2003 e 2006 (CoRDEIRo et al., 2010).

Análise documentalereuniöes.

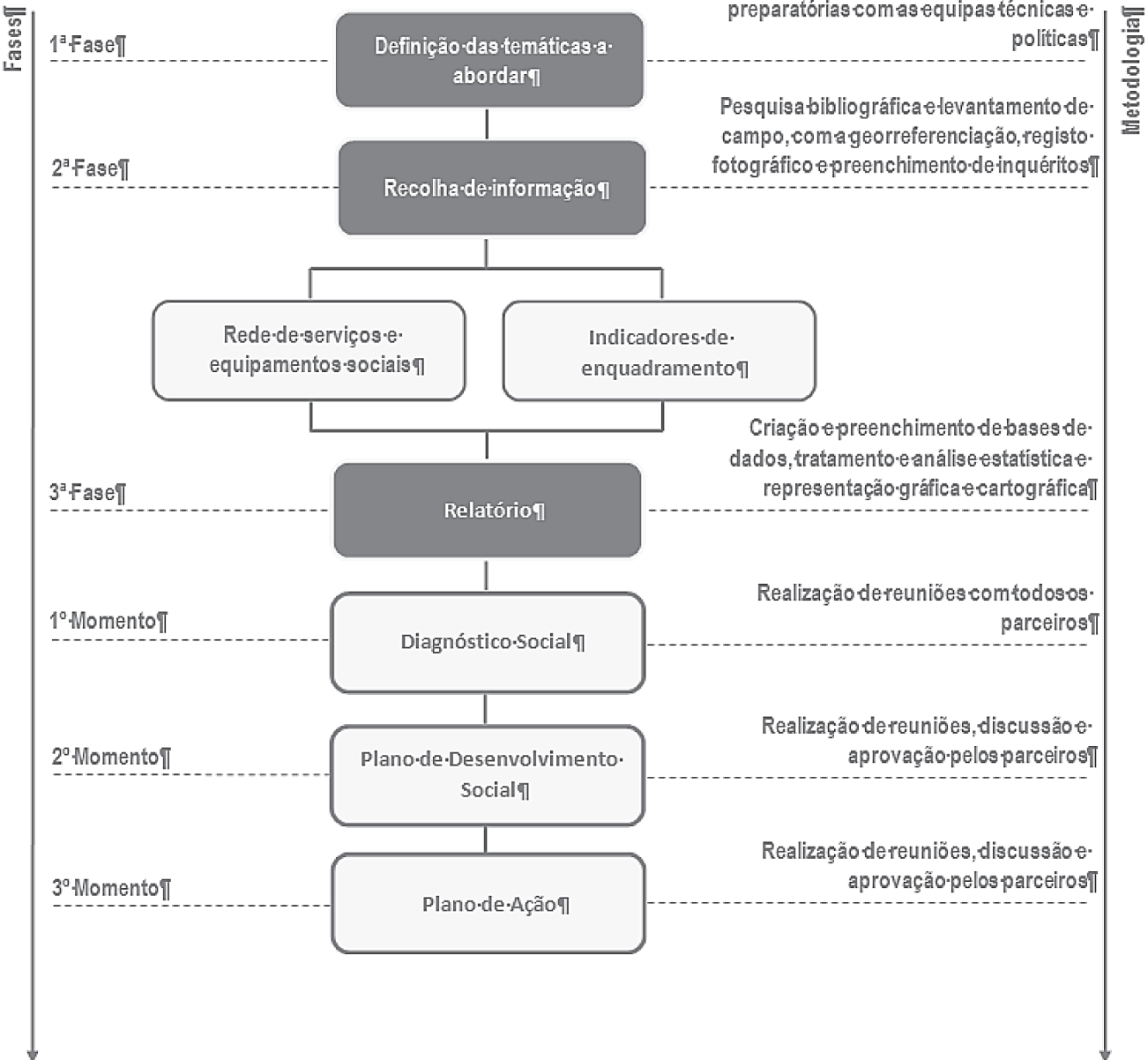

Figura 5

Fases de elaboração da Carta Social Municipal. 
A definição das temáticas a abordar assumiu-se como a primeira fase de desenvolvimento deste projeto, tendo como base a análise documental e a realização de reuniões de trabalho preparatórias entre a equipa técnica e os diferentes intervenientes no sistema social.

Neste momento revelou-se determinante a recolha de dois tipos de informação, uma relativa à rede de serviços e equipamentos sociais e outra centrada nas questões mais relevantes para a sua programação, que vai abordar os elementos necessários para a perceção da realidade presente e futura de um determinado território.

Para a recolha e posterior tratamento e análise estatística da informação relativa à rede de serviços e equipamentos mostrou-se indispensável a preparação de um conjunto de inquéritos e a criação de uma base de dados, no sentido de sistematizar a elevada quantidade de informação alfanumérica envolvida.

Esta base de dados assenta na construção de três tabelas, cada uma representativa de uma temática relacionada com o sistema social, designadamente as entidades gestoras, os equipamentos sociais e as respostas sociais. Estas tabelas especificam aspetos relacionados com a população utente e em lista de espera, os recursos humanos e materiais e as características do edificado.

O trabalho de inventariação da informação foi, assim, desenvolvido abarcando dois tipos de ação, uma em gabinete, onde é elaborada uma vasta pesquisa bibliográfica, e uma no exterior, na qual se efetua um exaustivo e moroso levantamento de campo, procedendo-se à georreferenciação de todos os equipamentos sociais com respostas sociais, ao registo fotográfico de todas as respostas sociais e ao preenchimento dos diferentes inquéritos.

Terminado o levantamento de campo inicia-se o processo de preenchimento da base de dados, previamente definida com os diversos atores no sistema social.

Após a conclusão destas etapas tornou-se possível a concretização da fase seguinte deste projeto, o relatório, constituído por três componentes distintas: o Diagnóstico Social, o Plano de Desenvolvimento Social e o Plano de Ação.

Uma vez que a área social obriga ao cumprimento das normativas legais anteriormente referidas, como se observa, o projeto agora apresentado foi estruturado com base nos três instrumentos de planeamento que o "Programa Rede Social" propõe e assume como essenciais. Deste modo, não só se dá resposta à necessidade da autarquia em termos de documento orientador da estratégia de intervenção na rede de serviços e equipamentos sociais a implementar, como se dá igualmente resposta às responsabilidades da autarquia perante a própria Segurança Social.

\subsection{Diagnóstico Social}

O Diagnóstico Social assume-se como um instrumento dinâmico, participado e que deve permitir uma compreensão global da realidade social de um determinado território, não só ao nível dos seus limites administrativos, mas fundamentalmente dos diferentes setores (ou freguesias) que o compõem. Deverá incluir a identificação das necessidades e a deteção dos problemas prioritários e respetivas causalidades, em como dos recursos e potencialidades locais, que constituem reais oportunidades de desenvolvimento.

Este documento foi estruturado de forma a integrar dois tipos de análise diferenciados. No primeiro realiza-se um enquadramento do Município, o qual integra a caracterização do território, da demografia, que inclui as projeções demográficas a 2021, quer da população residente total, em geral, quer por população e grupo-alvo, em particular, da educação, da saúde e do lazer e turismo. No segundo efetua-se o tratamento e análise estatística e o respetivo diagnóstico da informação relativa aos mecanismos de ação social de combate à pobreza e à exclusão social, que incluem a rede de serviços e equipamentos sociais, as prestações pecuniárias (Rendimento Social de Inserção e Complemento Solidário para Idosos), as prestações em espécie (Programa Comunitário de Ajuda Alimentar a Carenciados), as outras políticas, programas e medidas e a Comissão de Proteção de Crianças e Jovens, e aos mecanismos de intervenção integrada, que integram a componente de apoio à família e a rede nacional de cuidados continuados integrados, avaliando-se a sua adequação à realidade municipal.

\subsection{Plano de Desenvolvimento Social}

O Plano de Desenvolvimento Social é um instrumento de planeamento do "Programa Rede Social", onde, a partir das prioridades do Plano Nacional de Ação para a Inclusão (PNAl) ${ }^{1}$, se determinam os eixos

${ }^{1}$ No quadro do Processo Europeu de Inclusão Social e de acordo com as orientações aprovadas e definidas pelo Conselho Europeu de Nice, cada Estado-Membro produz os seus PNAl's. O PNAl português assume-se como o instrumento de construção de uma estratégia europeia no plano social, mas radica, fundamentalmente, no seu valor específico enquanto instrumento nacional de consolidação das políticas portuguesas de reforço da coesão nacional. O último PNAl é o referente ao horizonte temporal 2008-2010, pelo que, uma vez que ainda não surgiu um novo documento, continuam a vigorar as prioridades por este definidas. 
de intervenção e os objetivos para um horizonte temporal de 3 anos.

A definição das linhas orientadoras do desenvolvimento local e das prioridades de intervenção é realizada pelo Conselho Local de Ação Social (CLAS) com base no Diagnóstico Social anteriormente aprovado.

O Plano de Desenvolvimento Social assume-se, assim, como um documento estruturante, participado e prospetivo que é acordado como matriz orientadora para a dinamização e articulação das políticas sociais e das medidas concretas de um território municipal para os próximos anos.

Trata-se de um instrumento autorregulável das orientações estratégicas e das práticas e iniciativas no campo das respostas aos problemas sociais, que resulta da coautoria das diversas instâncias e protagonistas, que implica processos dinâmicos de monitorização, funcionamento e avaliação e, sobretudo, que assegura a partilha do compromisso e da responsabilidade social, por via de parcerias múltiplas.

Enquanto elemento essencial do processo de planeamento estratégico, o Plano de Desenvolvimento Social é um instrumento de definição conjunta e negociada de objetivos que visa a produção de efeitos corretivos ao nível da redução da pobreza e da exclusão social, mas também preventivos e indutores de processos de mudança.

A sua elaboração segue uma metodologia participativa, tentando-se que todos os parceiros e todas as redes existentes no território municipal estejam representados. Concluído o seu processo de construção, segue-se a sua aprovação em CLAS e a elaboração do Plano de Ação.

A base de trabalho para a sua elaboração é o Diagnóstico Social, que tem como suporte a realidade do município e, mais concretamente, as carências e problemáticas sociais existentes e previstas.

Deste modo, tenta-se não seguir a lógica de definir as prioridades de intervenção para o território municipal a partir dos programas nacionais, mas sim que a linha orientadora do desenvolvimento local seja um diagnóstico participado por todos os atores que se encontram a trabalhar no terreno.

Neste contexto, um Plano de Desenvolvimento Social deve ter como objetivo final a melhoria da qualidade de vida e bem-estar dos utentes, especialmente dos mais carenciados e vulneráveis, através da criação de respostas sociais adaptadas às suas reais necessidades, não só numa lógica da simples análise atual, mas fundamentalmente numa tentativa de antecipar alguns dos problemas que vão afetar o território num futuro próximo (ou médio).

Contudo, não devem aqui ser integrados problemas cuja resolução seja de difícil concretização ou que saiam demasiado fora do âmbito da "Rede Social".

Pretende-se, assim, efetuar um Plano de Desenvolvimento Social prático, útil e realista, que vá ao encontro dos interesses de todos os parceiros envolvidos (Quadro I).

\subsection{Plano de Ação}

O Plano de Ação é um instrumento de planeamento do "Programa Rede Social", onde, a partir das prioridades do PNAl e dos eixos de intervenção e objetivos identificados no Plano de Desenvolvimento Social, se determinam as prioridades, as ações, as metodologias e os parceiros para um horizonte temporal de um $a_{n o}^{2}$.

${ }^{2}$ A experiência tem vindo a mostrar que o horizonte temporal de apenas um ano é claramente curto, razão pela qual se observa que a esmagadora maioria das ações propostas acabam por ser concretizadas em períodos mais longos.

Quadro I

Plano Desenvolvimento Social.

\begin{tabular}{|c|c|c|c|c|c|}
\hline Prioridades & Eixos de Intervenção & Problemas & Objectivos & Acções & Cronograma \\
\hline $\begin{array}{l}\text { Prioridade 2: Corrigir as desvantagens nos níveis de qualificações como } \\
\text { meio de prevenir a exclusão e interromper os ciclos de pobreza }\end{array}$ & $\begin{array}{l}\text { Emprego, Formação } \\
\text { e Qualificação }\end{array}$ & & & & \\
\hline $\begin{array}{c}\text { Prioridade 1: Combater a pobreza das crianças e dos idosos, através de } \\
\text { medidas que assegurem os seus direitos básicos de cidadania } \\
\text { Prioridade 3: Ultrapassar as discriminações, através da integração das } \\
\text { pessoas com deficiência e dos imigrantes }\end{array}$ & $\begin{array}{l}\text { Intervenção Familiar } \\
\text { e Parental }\end{array}$ & & & & \\
\hline $\begin{array}{c}\text { Prioridade 1: Combater a pobreza das crianças e dos idosos, através de } \\
\text { medidas que assegurem os seus direitos básicos de cidadania } \\
\text { Prioridade 3: Ultrapassar as discriminações, através da integração das } \\
\text { pessoas com deficiência e dos imigrantes }\end{array}$ & $\begin{array}{c}\text { Capacitação da } \\
\text { Comunidade e das } \\
\text { Instituições }\end{array}$ & & & & \\
\hline $\begin{array}{c}\text { Prioridade 1: Combater a pobreza das crianças e dos idosos, através de } \\
\text { medidas que assegurem os seus direitos básicos de cidadania } \\
\text { Prioridade 3: Ultrapassar as discriminações, através da integração das } \\
\text { pessoas com deficiência e dos imigrantes }\end{array}$ & $\begin{array}{l}\text { Informação e } \\
\text { Acessibilidades }\end{array}$ & & & & \\
\hline
\end{tabular}


Trata-se de um documento de ação para a concretização de uma estratégia municipal de intervenção social e dá resposta às linhas orientadoras do desenvolvimento local e às prioridades de intervenção definidas pelo CLAS com base no Diagnóstico Social, nos seus níveis de ação supraconcelhio e concelhio.

Nele devem constar os recursos a utilizar, nomeadamente materiais, relacionais e políticos, as competências específicas necessárias e as redes de relacionamento comunitário e familiar da população-alvo existentes.

À semelhança do Plano de Desenvolvimento Social, a elaboração do Plano de Ação segue uma metodologia participativa, tentando-se que todos os parceiros e todas as redes existentes no território municipal estejam representados. De igual modo, concluído o seu processo de construção, segue-se a sua aprovação em CLAS.

Assume-se, assim, como um documento operacional, concertado e concretizado pelos diferentes atores que se encontram a trabalhar no território municipal.

Através do Plano de Ação pretende-se, deste modo, mobilizar ativamente os agentes públicos e privados e a sociedade civil para a dinamização e articulação de políticas sociais e de medidas concretas que visem promover a otimização dos recursos existentes e previstos, a sustentabilidade, a articulação, a participação, a inovação e a coesão necessárias para a consolidação de uma intervenção social, estrategicamente planeada e competitiva e inserida num quadro social mais justo e numa sociedade inclusiva.

Este instrumento de planeamento tem por objetivo tornar clara e lógica a sequência das atividades previstas e pretende-se a produção de efeitos corretivos ao nível da redução da pobreza e da exclusão social, mas também preventivos e indutores de processos de mudança.

As propostas apresentadas são direcionadas para problemas e grupos-alvo específicos e vão privilegiar a otimização dos recursos endógenos, no sentido de evitar a dispersão de meios financeiros, materiais e hu- manos, e a articulação com instrumentos nacionais, regionais e locais.

As atividades previstas no Plano de Ação têm de ser observadas de acordo com uma perspetiva de continuidade e de interligação, dado nem sempre ser possível a sua total concretização no decorrer do prazo de um ano (Quadro II).

\section{Parâmetros orientadores da Carta Social Municipal}

Todo o processo de construção de uma "Carta Social Municipal" deve assentar numa visão estratégica de criação de territórios socialmente coesos, dispondo de uma rede de serviços e equipamentos sociais adequadamente dimensionada e distribuída, que permita responder com elevados níveis de eficiência às carências e problemáticas sociais existentes, só possível através do cumprimento de um conjunto de pressupostos orientadores das intervenções:

- Elevar os níveis de resposta da rede de serviços e equipamentos sociais - Melhorar a oferta da rede de serviços e equipamentos sociais através da identificação nas respostas sociais de fragilidades e/ou carências atuais ou previstas, quer em função da provável evolução das diferentes populações e grupos-alvo, quer em função das crescentes necessidades da população, resultado da evolução do próprio conceito de família e da emergência de novos grupos sociais carenciados, que advêm da alteração dos padrões de vida. Este incremento traduz-se em diferentes estratégias de atuação, entre as quais se destacam a beneficiação e/ou adaptação das soluções existentes e/ou a criação de respostas sociais inexistentes;

- Qualificar as respostas sociais - Aumentar a qualidade do serviço prestado ao utente através da melhoria das condições humanas, ma-

Quadro II

Plano Desenvolvimento Social.

\begin{tabular}{|c|l|l|l|l|l|l|l|}
\hline Eixos de Intervenção & $\begin{array}{c}\text { Objectivos } \\
\text { Específicos }\end{array}$ & $\begin{array}{c}\text { Número da } \\
\text { Acção }\end{array}$ & Data de início & Data de Fim & $\begin{array}{c}\text { Descrição da } \\
\text { Acção }\end{array}$ & $\begin{array}{c}\text { Metodologia } \\
\text { Responsável } \\
\text { pela Acção }\end{array}$ & $\begin{array}{c}\text { Outros } \\
\text { Parceiros } \\
\text { Envolvidos }\end{array}$ \\
\hline $\begin{array}{c}\text { Emprego, Formação e } \\
\text { Qualificação }\end{array}$ & & & & & & \\
\hline $\begin{array}{c}\text { Intervenção Familiar e } \\
\text { Parental }\end{array}$ & & & & & & & \\
\hline $\begin{array}{c}\text { Capacitação da Comunidade } \\
\text { e das Instituições }\end{array}$ & & & & & & & \\
\hline Informação e Acessibilidades & & & & & & \\
\hline
\end{tabular}


teriais e operacionais da rede de serviços e equipamentos sociais;

- Melhorar a distribuição espacial da rede de serviços e equipamentos sociais - Criar uma rede de serviços e equipamentos sociais corretamente estruturada em que as respostas sociais se organizem espacialmente de acordo com os critérios locativos definidos. Este ordenamento deve ter como princípio base a redução das assimetrias territoriais e o adaptar da oferta à procura.

Para atingir esta finalidade, o projeto "Carta Social: uma estratégia de intervenção integrada" apresenta dois grandes conjuntos de objetivos, que parcialmente se devem já encontrar analisados no Diagnóstico Social:

\section{Objetivos operacionais:}

- Diagnosticar a oferta da rede serviços e equipamentos sociais;

- Identificar as principais carências e problemáticas sociais;

- Determinar os domínios e os locais de intervenção social prioritária;
- Realizar a projeção demográfica da população residente, total e por grupo-alvo, e de indicadores de enquadramento, como a taxa de natalidade, o índice de envelhecimento e o coeficiente de dependência;

- Definir os critérios de programação dos serviços e equipamentos sociais.

Objetivos estratégicos:

- Orientar os investimentos municipais em serviços e equipamentos sociais;

- Orientar os investimentos das entidades parceiras públicas, privadas e cooperativas;

- Fornecer orientações para o Plano Director Municipal (PDM).

Este processo de planeamento obedece, naturalmente, a parâmetros orientadores, que se subdividem em princípios base, critérios locativos e tipos de intervenção (Figura 6).

A definição das linhas orientadoras do desenvolvimento local e das prioridades de intervenção devem basear-se em quatro princípios base:

- Igualdade - Garantir a igualdade de oportunidade no acesso aos serviços e equipamentos sociais;

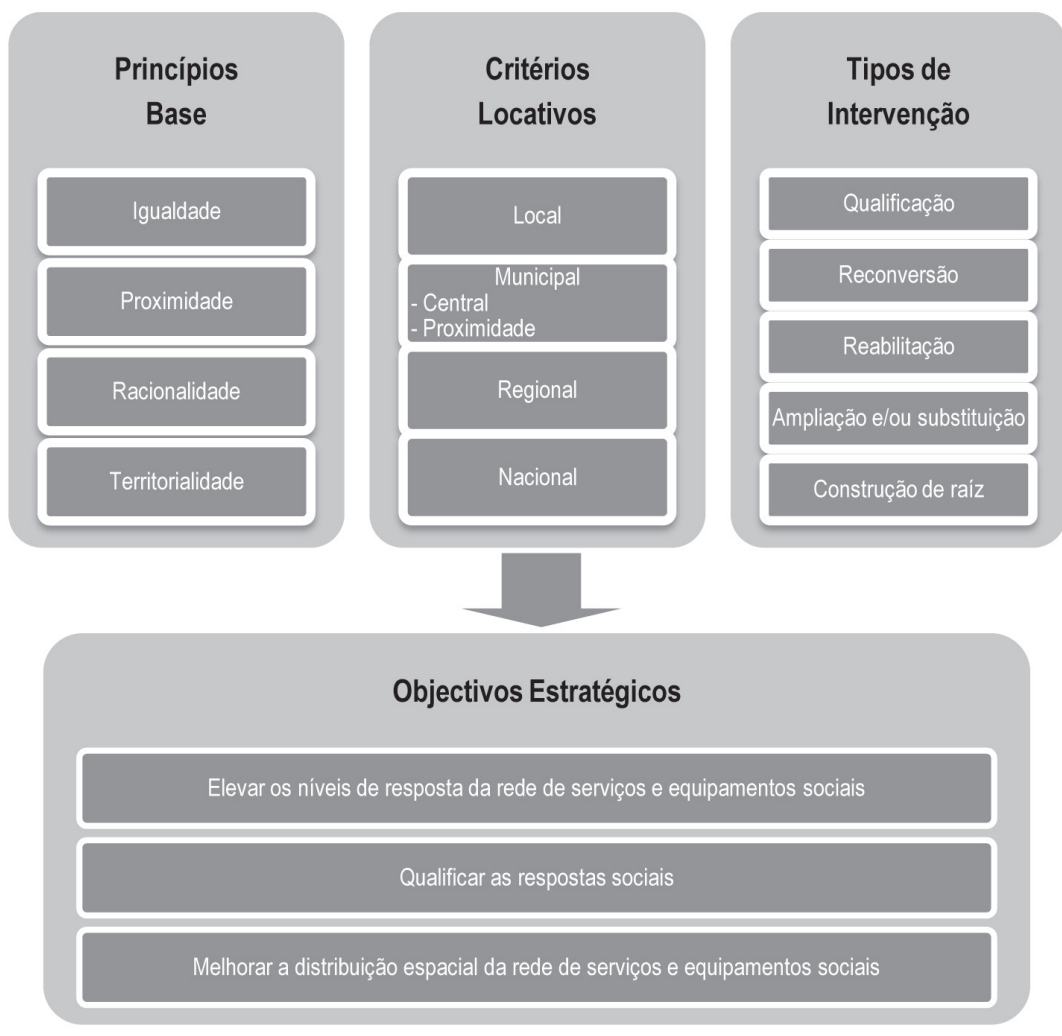

Figura 6

Parâmetros orientadores da programação da rede de serviços e equipamentos sociais. 
- Proximidade - Assegurar a proximidade dos utentes aos equipamentos sociais;

- Racionalidade - Permitir a maximização dos resultados e a diminuição da dispersão de recursos financeiros, materiais e humanos;

- Territorialidade - Contribuir para a estruturação do território.

Por seu turno, o modelo territorial que define a área de intervenção de cada resposta social deve encontrar-se estruturado em quatro critérios locativos, cada um correspondente a um nível de atuação:

- Local - A localização dos serviços e equipamentos sociais depende da proximidade ao grupoalvo, correspondendo essencialmente a respostas sociais para os grupos-alvo "Crianças e Jovens" e "Pessoas Idosas", que se pretendem universais e difundidas por todo o território municipal, como é o caso dos Centros de Dia, dos Estabelecimentos de Educação Pré-escolar e mesmo das creches em territórios de elevada densidade;

- Municipal - Este nível de atuação subdivide-se em dois subníveis:

- Central - Serviços e equipamentos sociais dirigidos para grupos-alvo com um padrão de distribuição espacial difuso, necessitando, assim, de uma localização acessível;

- Proximidade - Serviços e equipamentos sociais vocacionados para grupos-alvo específicos com um padrão de distribuição espacial pontual e concentrado num determinado local, justificando-se, assim, que seja aí localizado, principalmente considerando o facto de se dirigir, maioritariamente, a população com carências económicas e dificuldades de mobilidade.

- Regional - Serviços e equipamentos sociais geridos pela Administração Central de nível regional e com um grau de especificidade elevado, como é o caso das respostas sociais direcionadas para "Pessoas com Deficiência", "Pessoas Toxicodependentes" e "Pessoas Vítimas de Violência Doméstica";

- Nacional - Serviços e equipamentos sociais geridos pela Administração Central de nível nacional e com um grau de especificidade muito elevado.

A concretização efetiva das respostas sociais assenta em diferentes tipos de intervenção, sendo que qualquer que seja a opção, esta encontra-se, naturalmente, sujeita a critérios técnicos e legais. As ações a realizar podem ser tanto ao nível das características dos recursos humanos, como ao nível das características dos recursos materiais e podem ser de cinco tipos:

- Qualificação - Pode ser entendida segundo a componente dos recursos humanos ou segundo a vertente dos recursos materiais. No que respeita aos recursos humanos, remete para a questão da quantidade e qualidade. A primeira é regulamentada por critérios técnicos e legais, nem sempre cumpridos, frequentemente por razões económicas, enquanto a segunda pressupõe a valorização do pessoal afeto, com a finalidade de reforçar a sua competência e eficácia. Relativamente aos recursos materiais, remete para a melhoria das condições de operacionalidade dos equipamentos sociais, tendo como objetivo aumentar o conforto, a salubridade, a funcionalidade, a segurança e a acessibilidade das construções, assim como a autonomia energética e qualidade ambiental;

- Reconversão - Aplica-se a equipamentos sociais onde passam a funcionar respostas diferentes daquelas para as quais foram inicialmente construídos;

- Reabilitação - Dirige-se a equipamentos sociais que apresentam problemas de conservação, atendendo a que muitos funcionam em instalações antigas e demonstram necessidades de obras de manutenção;

- Ampliação e/ou substituição - Direciona-se a equipamentos sociais que não apresentam as condições operacionais necessárias para o exercício das suas funções. Estas condições operacionais podem corresponder a limitações físicas das instalações, como a degradação, a dimensão e a coabitação de respostas sociais diferentes, ou a limitações materiais, muitas vezes relacionadas com questões financeiras das entidades gestoras;

- Construção de raíz - Relaciona-se com a construção de equipamentos sociais para respostas já existentes ou para a criação de novas respostas sociais.

Para além dos parâmetros orientadores, as intervenções a realizar devem ainda considerar um outro conjunto de fatores, como:

- Taxa de cobertura das respostas sociais;

- Identificação de grupos sociais com resposta nula, insuficiente ou excedentária;

- Nível de atuação das respostas sociais;

- Distribuição etária da população residente; 
- Existência de população que não disponha de apoio familiar e revele carências;

- Disponibilidade de pessoal técnico com formação adequada;

- Proximidade a serviços de apoio na área da saúde, do social e da educação;

- Localização em zonas habitacionais, excetuando o caso de algumas respostas sociais específicas;

- Contiguidade a redes de acessibilidades e de transportes;

- Acesso a infraestruturas de saneamento básico e a redes de energia elétrica, água e telefone;

- Afastamento de áreas poluídas, ruidosas, insalubres ou outras que, pela sua natureza, possam pôr em causa a integridade física ou psíquica dos utentes.

O projeto "Carta Social: uma estratégia de intervenção integrada", tal como idealizado e atendendo às metodologias utilizadas, pode ser aplicado a diferentes escalas territoriais, desde a municipal, à nacional, passando pela regional e distrital. Naturalmente é na passagem à escala intermunicipal que as potencialidades deste projeto parecem ser mais evidentes (Figura 7). $\mathrm{Na}$ realidade, e como se observa no caso apresentado, este mostra, de uma forma clara, que as fronteiras ad- ministrativas são pouco compatíveis com a prática do ordenamento e planeamento do território e em particular do planeamento de equipamentos coletivos, já que aquelas raramente são coincidentes com as fronteiras naturais e humanas, pelo que só se torna possível falar num verdadeiro planeamento quando se analisa o território como um todo.

Como se pode constatar, o que se apresenta como debilidade na oferta de cada um dos municípios - setor Nordeste da Figueira da Foz e Noroeste de Montemoro-Velho - acaba numa análise intermunicipal por evidenciar um amplo setor do território onde a oferta da resposta social Lar de Idosos é inexistente, o que determina em termos de planeamento o equacionar desse amplo setor como área prioritária de intervenção. Deste modo, passa a ser evidente que a realização deste tipo de documento à escala da NUTIII ou das Comunidades Intermunicipais pode fornecer informação que a análise municipal não consegue.

\section{Algumas considerações finais}

A criação do projeto "Carta Social: uma estratégia de intervenção integrada" surgiu no seguimento da

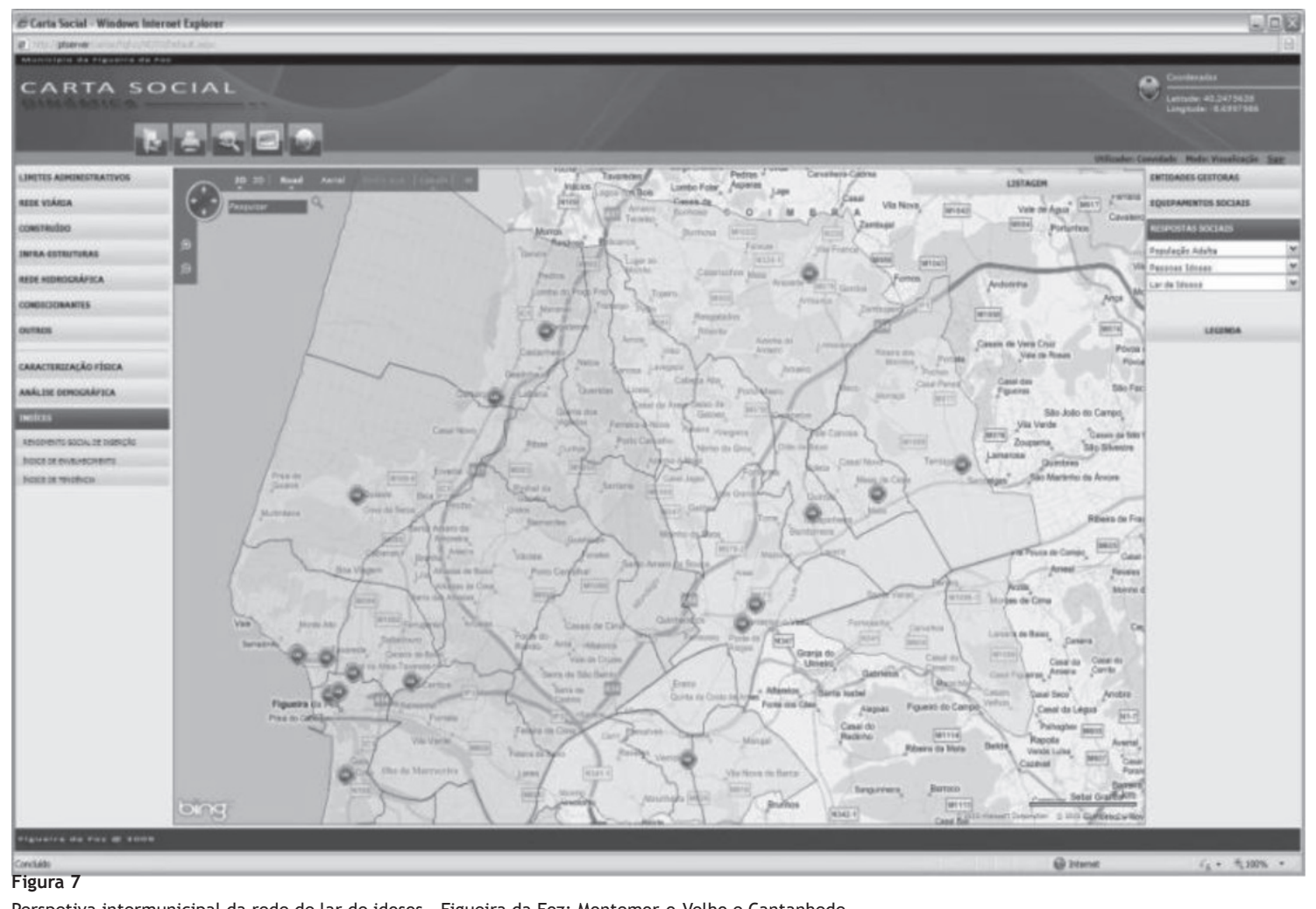

Perspetiva intermunicipal da rede de lar de idosos - Figueira da Foz; Montemor-o-Velho e Cantanhede 
necessidade de desenvolver um instrumento de planeamento no qual deveria ser integrada a informação mais relevante relativa à rede de serviços e equipamentos sociais de um determinado território.

Com o desenvolvimento deste instrumento de planeamento pretendeu-se, assim, a criação de espaços social e territorialmente coesos, dispondo de uma rede de serviços e equipamentos sociais adequadamente dimensionada e distribuída, que permita responder com elevados níveis de eficiência às carências e problemáticas sociais existentes, bem como tentar antecipar aquelas que a um ritmo acelerado vão surgindo na nossa sociedade, resultado das transformações sociais.

Para o cumprimento da finalidade a que se propôs, este projeto é constituído por três partes distintas: o Diagnóstico Social, o Plano de Desenvolvimento Social e o Plano de Ação.

Cada um destes instrumentos de planeamento apresenta objetivos e metodologias diferenciadas. Enquanto o Diagnóstico Social se apresenta como um instrumento de identificação das necessidades e problemas prioritários, bem como dos recursos, potencialidades e constrangimentos de cada território, o Plano de Desenvolvimento Social, com base nas prioridades definidas no Diagnóstico Social, determina eixos de intervenção e objetivos estratégicos para um horizonte temporal de três anos. Por seu turno, estes eixos de intervenção e objetivos estratégicos são operacionalizados através de um Plano de Ação anual.

Através destas ferramentas pretendeu-se mobilizar ativamente os agentes públicos e privados e a sociedade civil para a dinamização e articulação de políticas sociais e de medidas concretas que visem promover a otimização dos recursos existentes e previstos.

Mas para que a "Carta Social" pudesse de facto atingir os seus objetivos, esta incluiu ainda um segundo conjunto de questões relevantes para a programação da rede de serviços e equipamentos sociais. 0 conhecimento do território nas suas mais variadas vertentes - demográfica, socioeconómica e física - assume um papel preponderante para a perceção da sua realidade presente e futura.

Além de todas estas componentes que o projeto integra, conceitos como a sustentabilidade, a articulação, a participação, a inovação e a coesão foram também fundamentais para a consolidação da intervenção social, que se quer estrategicamente planeada e competitiva e inserida num quadro social justo e numa sociedade inclusiva.

Contudo, e embora este documento tente ser um retrato completo da realidade social de um determina- do território, integrando não só todos os aspetos relacionados com a rede de serviços e equipamentos sociais, mas também a caracterização do território, e assuma uma dupla vertente de diagnóstico e de intervenção planeada, um projeto com estas características nunca está terminado, pelo que a "Carta Social" manter-se-á permanentemente aberta às alterações que certamente se irão verificar nos mais variados domínios.

A resolução de um problema social não significa mais do que o início de outro tipo de problemática e para os mais recentes e até mesmo velhos problemas encontrar-se-ão novas soluções, tanto em termos de extensão numérica, como de qualidade de desempenho, como ainda de conceitos e de integração no conjunto de políticas sociais em que a rede de serviços e equipamentos sociais se insere.

\section{Bibliografia}

Cordeiro, A. M. Rochette (coord.) (2010) - Carta de Equipamentos Sociais do Município da Figueira da Foz. Faculdade de Letras da Universidade de Coimbra, Coimbra (relatório policopiado).

Cordeiro, A. M. Rochette (coord) (2011) - Carta Social Dinâmica do Município de Montemor-o-Velho: Uma Estratégia de Intervenção Planeada. Faculdade de Letras da Universidade de Coimbra, Coimbra.

Cordeiro, A. M. Rochette (coord.) (2011) - Carta Social Dinâmica do Município de Tondela. Pensarterritório, Lda, Coimbra.

Cordeiro, A. M. Rochette (coord.) (2012) - Carta Social Dinâmica do Município de Alvaiázere: Uma Estratégia de Intervenção Planeada. Faculdade de Letras da Universidade de Coimbra, Coimbra (em publicação).

Cordeiro, A. M. Rochette; Caridade, P. J. S. B.; Santos, L. I. R.; Paredes, L. C. M. C. R.; Coelho, S.I. C. e Freitas, A. M. (2007-2008) - "O contributo dos sistemas de informação geográfica para o ordenamento e planeamento do território: As cartas sociais dinâmicas". Cadernos de Geografia, n. ${ }^{\circ} 26$ e 27, Faculdade de Letras da Universidade de Coimbra, Coimbra.

Ré, O. (coord.); Martins, A. C.; Dias, E. S.; Ramos, E.; Guerra, F.; Miralto, I.; Nogueira, J. M.; Silveira, R. e Costa, V. (2000) - Carta Social - Rede de serviços e equipamentos. Departamento de Estudos, Prospectiva e Planeamento, Lisboa.

Rodrigues, F. (Coord); Gonçalves, A.; Guerra, F.; Matos, G. e Pignatelli, M. C. (2008) - Plano Nacional de Ação para a Inclusão.

Constituição da República, Lei Constitucional n. ${ }^{\circ} 1 / 2005$ de 12 de Agosto, Diário da República, n. ${ }^{\circ}$ 155, I Série - A, Lisboa. 
Resolução do Conselho de Ministros n. ${ }^{\circ} 197 / 97$ de 18 de Novembro de 1997, Diário da República, n. ${ }^{\circ} 267$ Série I, Concelho de Ministros, Lisboa.

Declaração de Rectificação n. ${ }^{\circ}$ 10-0/98, Diário da República, n. ${ }^{\circ} 125$, Série I, Concelho de Ministros, Lisboa.
Despacho Normativo n. ${ }^{\circ}$ 8/2002 de 12 de Fevereiro, Diário da República, n. ${ }^{\circ} 36$, Série I, Ministério do Trabalho e da Solidariedade, Lisboa.

Decreto-Lei n. ${ }^{\circ}$ 115/2006 de 14 de Junho, Diário da República, n. ${ }^{\circ} 114$, Série I, Ministério do Trabalho e da Solidariedade Social, Lisboa. 